\title{
BMJ Open Prevalence of dyslipidaemia and awareness of blood cholesterol levels among community-living people: results from the Longevity check-up 7+ (Lookup 7+) cross-sectional survey
}

Emanuele Marzetti, ${ }^{1}$ Riccardo Calvani, ${ }^{1}$ Anna Picca, ${ }^{1}$ Alex Sisto, ${ }^{2}$ Matteo Tosato, ${ }^{1}$ Anna Maria Martone, ${ }^{1}$ Elena Ortolani, ${ }^{1}$ Sara Salini, ${ }^{1}$ Teodosio Pafundi, ${ }^{1}$ Angelo Santoliquido, ${ }^{3}$ Luca Santoro, ${ }^{3}$ Roberto Bernabei, ${ }^{1}$ Francesco Landi ${ }^{1}$

To cite: Marzetti E, Calvani R, Picca A, et al. Prevalence of dyslipidaemia and awareness of blood cholesterol levels among community-living people: results from the Longevity checkup 7+ (Lookup 7+) crosssectional survey. BMJ Open 2018;8:e21627. doi:10.1136/ bmjopen-2018-021627

- Prepublication history for this paper is available online. To view these files, please visit the journal online (http://dx.doi. org/10.1136/bmjopen-2018021627).

Received 10 January 2018 Revised 21 May 2018

Accepted 24 May 2018

Check for updates

(C) Author(s) (or their employer(s)) 2018. Re-use permitted under CC BY-NC. No commercial re-use. See rights and permissions. Published by BMJ.

${ }^{1}$ Department of Geriatrics, Neurosciences and Orthopaedics, Catholic University of the Sacred Heart, Rome, Italy ${ }^{2}$ College of Medicine, Drexel University, Philadelphia, Pennsylvania, USA ${ }^{3}$ Department of Internal Medicine, Catholic University of the Sacred Heart, Rome, Italy

Correspondence to

Dr Anna Picca;

anna.picca1@gmail.com

\section{ABSTRACT}

Objective The aim of the present study was to investigate the prevalence of abnormal cholesterol levels and to explore awareness of cholesterol values in an unselected sample of community-living adults.

Design Cross-sectional survey.

Setting Exhibitions, malls and health promotion campaigns across Italy.

Participants 3535 community dwellers aged 18-98 years were enrolled between September 2016 and June 2017. Analyses were conducted in 3040 participants, after excluding 495 enrolees on cholesterol-lowering medications.

Main outcome measures Total blood cholesterol levels and awareness of cholesterol values.

Results Abnormal blood cholesterol values were found in 1961 (64.5\%) of participants with no differences between genders $(p=0.06)$. Among those who believed they had normal cholesterol levels, only $48 \%$ had values below $200 \mathrm{mg} / \mathrm{dL}$. More than $40 \%$ had cholesterol values between 200 and $240 \mathrm{mg} / \mathrm{dL}$, and around $10 \%$ had values $>240 \mathrm{mg} / \mathrm{dL}$. More than one-third of participants had not measured cholesterol in the last year. Among them, only $36 \%$ had normal cholesterol levels.

Conclusions Abnormal blood cholesterol is highly prevalent in our sample of Italian community dwellers, with less than half of participants being aware of their cholesterol levels.

\section{INTRODUCTION}

Cardiovascular disease (CVD) is the leading cause of death worldwide and accounts for the largest share of healthcare expenditure in many countries. ${ }^{1}$ Despite the prevention strategies adopted in recent decades, CVD still affects one in three adults and causes the same proportion of deaths. ${ }^{23}$ Whereas primary and secondary prevention addresses individuals who present with one or more risk factors or have already sustained a cardiovascular event,
Strengths and limitations of this study

- The unconventional setting in which the research was carried out and the very few exclusion criteria adopted allowed recruitment of 'real-world' people across a wide age spectrum.

- The questionnaire used for data collection and the specific assessments conducted were developed based on previous experiences in similar surveys.

- Study variables, including cardiovascular health metrics, were collected through a standardised questionnaire and objective measurements.

- The use of random cholesterol and glucose determinations could lead to overestimating both parameters.

- The type of evaluation and its setting could influence the assessment of health metrics.

primordial prevention is recommended for improving cardiovascular health on a national scale. ${ }^{45}$ Although CVD prevention represents one key action of healthcare programmes, little data are available concerning the awareness about the importance of prevention in the general population. Screening for dyslipidaemia should be considered in all men $\geq 40$ years of age and in women $\geq 50$ years of age or postmenopausal, particularly in the presence of other CVD risk factors. Yet, the prevalence of positive cardiovascular health metrics, including ideal blood cholesterol values, is disappointingly low in the general population. ${ }^{6}$ The aims of the present study were to investigate the prevalence of high cholesterol levels and to explore awareness of cholesterol values in an unselected sample of community dwellers enrolled in the Longevity check-up 7+ (Lookup 7+) project. 


\section{METHODS}

The Lookup 7+ project is an ongoing initiative developed by the Department of Geriatrics of the Catholic University of the Sacred Heart (Rome, Italy). The project started on 1 June 2015 and was designed to promote the adoption of healthier lifestyles by raising awareness in the general population on major lifestyle behaviours and risk factors for chronic diseases. A team of medical doctors, researchers and nutritionists assessed people visiting public places (eg, malls, exhibition centres) and those adhering to prevention campaigns launched by our department. This approach was chosen because allowing for enrolling relatively unselected participants outside of conventional healthcare or research settings. The assessment protocol has been described in detail elsewhere. ${ }^{6}$ Candidate participants are considered to be eligible for enrolment if they are at least 18 years of age and provide written informed consent. Pregnancy, inability to perform functional tests, refusal of blood capillary check and unwillingness to give written informed consent are considered exclusionary.

\section{Participant and public involvement}

Although study participants or the public were not formally involved in the design of the study, the questionnaire used for data collection and the specific assessments conducted were developed based on previous experiences in similar surveys. ${ }^{6-10}$ Furthermore, at the end of the evaluation, participants were provided with their cardiovascular health metrics score ${ }^{11}$ along with suggestions on how to improve their lifestyle and on the eventual need for further assessments. Notably, as previously reported, ${ }^{10}$ among 6323 Lookup 7+ participants, the vast majority $(4917 ; 82 \%)$ declared to be very satisfied with the initiative, $688(14 \%)$ were satisfied, $148(3 \%)$ declared to be neither satisfied nor dissatisfied and only $49(1 \%)$ were not satisfied.

\section{Study sample}

As part of the Lookup 7+ initiative, 6323 individuals in different surveys and Italian cities were enrolled between 1 June 2015 and 30 June 2017. In the current study, we focused on surveys in which specific questions about the awareness of the importance of CVD prevention were considered. We therefore narrowed the sample to 3535 individuals enrolled in the following settings: Mese del Cuore 2016 (Rome, September-October 2016), La Romanina-Check your Longevity (Rome, December 2016), Mese del Cuore 2017 (Milan, March-April 2017), Health Ministry-Women's Day (Rome, April 2017), CamBio Vita (Catania, May, 2017), and COOP shopping centres (Bologna, Modena, Genoa, Rimini and Grosseto, May-June 2017). Depending on the setting, the initiative was advertised in newspapers, magazines and TV broadcasting. Visitors were also invited to participate by direct contact.

Persons on cholesterol-lowering drugs $(n=495)$ were excluded from the analyses. In principle, individuals who are taking cholesterol medications are already aware of this risk factor and have less of a need to be educated. Therefore, a final sample of 3040 individuals was considered.

\section{Data collection}

The Lookup 7+ visit was structured to collect the following information and data: informed consent, lifestyle interview (smoking and eating habits, habitual physical activity), blood pressure measurement, weight and height assessment, total blood cholesterol and glucose measurements and the chair stand test.

\section{Total blood cholesterol measurement}

Total blood cholesterol was measured from capillary blood samples using disposable reagent strips based on a reflectometric system with a MultiCare-In portable device (Biomedical Systems International srl, Florence, Italy). ${ }^{12}$ Before cholesterol measurement, participants were asked two questions about their cholesterol awareness: (1) 'How do you think your cholesterol level is?' with possible answers being: 'High', 'Normal' or 'I do not know'; and (2) 'Did you measure cholesterol in the last year?' with possible answers being 'Yes' or 'No'.

\section{Assessment of other cardiovascular health metrics}

Other parameters pertaining to major cardiovascular risk factors were assessed through closed questions and direct measurement. ${ }^{6}{ }^{11}$ Smoking habit was categorised as current or never/former smoker..$^{10}$ Body weight was measured through an analogue medical scale. Body height was measured using a standard stadiometer. Body mass index (BMI) was calculated as the weight $(\mathrm{kg})$ divided by the square of height $(\mathrm{m})$. Healthy diet was defined as the consumption of at least three portions of fruit and/or vegetables per day. ${ }^{8}$ For the calculation of daily intake of fruit and vegetables, we used the reference tables for the Italian population released by the Italian Society of Nutrition (SINU). Accordingly, three or more portions of fruit and/or vegetables correspond to more than $400 \mathrm{~g}$, which is the minimum amount recommended by the WHO. The use of three or more portions to identify a healthy diet is in line with Italian dietary habits for fruit and vegetables which are typically eaten during the main meals rather than as snacks. Reference amounts are available at http://www.sinu.it/html/cnt/larn.asp. A random blood glucose value was obtained from capillary blood samples using disposable reagent strips based on an amperometric system with the MultiCare-In device. ${ }^{12}$ Those who declared being diabetic and, according to international guidelines, ${ }^{13}$ those who presented with a random blood glucose level $\geq 200 \mathrm{mg} / \mathrm{dL}$ were considered to be diabetic. Blood pressure was measured with a clinically validated Omron M6 electronic sphygmomanometer (Omron, Kyoto, Japan), according to recommendations from international guidelines. ${ }^{14}$ Participants who declared being hypertensive and those with two systolic blood pressure measurements $\geq 140 \mathrm{~mm} \mathrm{Hg}$ and/ 
or two diastolic blood pressure values $\geq 90 \mathrm{~mm} \mathrm{Hg}$ were considered to be hypertensive. ${ }^{14}$

\section{Statistical analyses}

Continuous variables are expressed as mean $\pm \mathrm{SD}$, while categorical variables are shown as frequencies by absolute value and percentages. Descriptive statistics were used to describe demographic and key clinical characteristics of the study population according to gender. Differences in proportions and means of covariates between genders were assessed using the Fisher's exact test and t-test statistics, respectively.

The primary focus of the analytic plan was to explore the prevalence of high blood cholesterol across self-predicted cholesterol levels among individuals who had not checked their cholesterol in past year. Participants were grouped by blood cholesterol levels $(<200 \mathrm{mg} / \mathrm{dL}$ (normal); 200-240 mg/dL (moderate high); $>240 \mathrm{mg} / \mathrm{dL}$ (high)) and age ( $<45$ years (young); $45-65$ years (middleaged); $>65$ years $($ old $)$ ).

Logistic regression analysis was used to assess the association between clinical and lifestyle characteristics and cholesterol awareness. Univariate and adjusted models were performed for self-predicted cholesterol levels and for cholesterol checks in the past year. Candidate variables to be included in the logistic regression models were selected on the basis of their plausibility as risk factors for poor cholesterol awareness. We first estimated a crude prevalence rate ratio at $95 \% \mathrm{CI}$ and then controlled for age and gender. Finally, logistic regression analyses were computed including all the variables of interest (age, gender, smoking habit, healthy diet, physical activity, BMI, blood pressure and diabetes).

All analyses were performed using SPSS software (V.18.0, SPSS, Chicago, IL, USA).

\section{RESULTS}

Sample characteristics according to gender are shown in table 1 . The mean age of the 3040 participants was 56.6 years (SD 14.6, range 18-98 years), with 1858 $(61 \%)$ women. Men were more frequently physically active than women (59\% vs $53 \%$, respectively; $\mathrm{p}=0.002)$. Instead, women were more likely to follow a healthy diet compared with men (68\% vs 59\%, respectively; $\mathrm{p}<0.001)$. As expected, BMI and systolic and diastolic blood pressure were higher among men. The mean cholesterol level was higher in women than men $(215 \mathrm{mg} / \mathrm{dL}$ vs $211 \mathrm{mg} /$ $\mathrm{dL}$, respectively; $\mathrm{p}<0.001)$. However, the proportion of participants with normal cholesterol levels was similar in women and men ( $34 \%$ vs $36 \%$, respectively; $\mathrm{P}=0.06$ ).

When considering self-predicted cholesterol levels, $48 \%$ of men thought they had normal values compared with $39 \%$ of women $(\mathrm{p}<0.001)$ (table 1$)$. Figure 1 shows the prevalence of cholesterol levels according to self-predicted values. Among those who believed they had normal cholesterol levels, only $48 \%$ showed values $<200 \mathrm{mg} / \mathrm{dL}$.

\begin{tabular}{|c|c|c|c|c|}
\hline Characteristics & Total sample $(n=3040)$ & Men $(n=1182)$ & Women $(n=1858)$ & P values \\
\hline Age (years) & $56.6 \pm 14.6$ & $57.1 \pm 14.6$ & $56.3 \pm 14.5$ & 0.11 \\
\hline Smoking (yes) & $508(17)$ & $235(20)$ & $273(15)$ & $<0.001$ \\
\hline Physically active (yes) & $1674(55)$ & $692(59)$ & $982(53)$ & 0.002 \\
\hline Healthy diet (yes) & $1958(63)$ & $698(57)$ & $1260(66)$ & $<0.001$ \\
\hline $\operatorname{BMl}\left(\mathrm{kg} / \mathrm{m}^{2}\right)$ & $25.7 \pm 4.4$ & $26.7 \pm 3.8$ & $25.0 \pm 4.7$ & $<0.001$ \\
\hline $\mathrm{SBP}(\mathrm{mm} \mathrm{Hg})$ & $123 \pm 16.4$ & $126 \pm 14.8$ & $121 \pm 17.1$ & $<0.001$ \\
\hline $\mathrm{DBP}(\mathrm{mm} \mathrm{Hg})$ & $73 \pm 10$ & $76 \pm 10$ & $72 \pm 10$ & $<0.001$ \\
\hline Total blood cholesterol (mg/dL) & $213.4 \pm 32.2$ & $210.8 \pm 32.1$ & $215.1 \pm 32.1$ & $<0.001$ \\
\hline \multicolumn{5}{|l|}{ Cholesterol level categories } \\
\hline$<200 \mathrm{mg} / \mathrm{dL}$ & $1079(36)$ & $439(37)$ & $640(34)$ & 0.06 \\
\hline $200-240 \mathrm{mg} / \mathrm{dL}$ & $1465(48)$ & $572(48)$ & $893(48)$ & \\
\hline$>240 \mathrm{mg} / \mathrm{dL}$ & $496(16)$ & $171(15)$ & $325(18)$ & \\
\hline Blood glucose (mg/dL) & $100.7 \pm 20.9$ & $101.7 \pm 23.6$ & $100.1 \pm 19.1$ & 0.04 \\
\hline Cholesterol check in past year (no) & $1201(40)$ & $458(39)$ & $735(40)$ & 0.66 \\
\hline \multicolumn{5}{|l|}{ Self-predicted cholesterol level } \\
\hline Normal & $1285(42)$ & $565(48)$ & $720(39)$ & $<0.001$ \\
\hline High & $1148(38)$ & $404(34)$ & $744(40)$ & \\
\hline Don't know & $607(20)$ & $213(18)$ & $394(21)$ & \\
\hline
\end{tabular}

Data are given as numbers (percentages) for smoking, physical activity, healthy diet, cholesterol level categories, cholesterol screening and self-predicted cholesterol; for all other variables, means and SD are reported.

$\mathrm{BMI}$, body mass index; DBP, diastolic blood pressure; SBP, systolic blood pressure. 

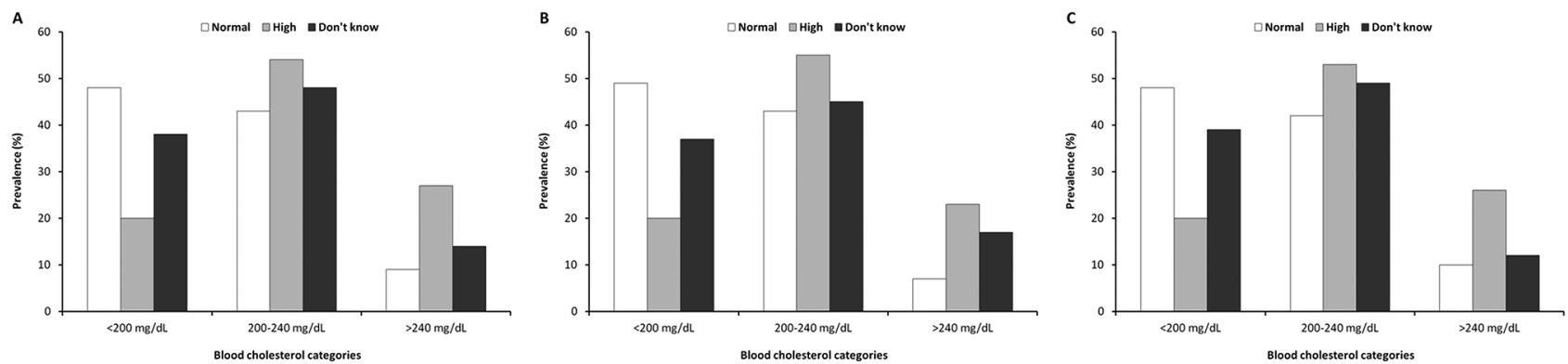

Figure 1 Total blood cholesterol according to self-predicted cholesterol levels in the whole sample (A), in men (B) and in women (C).

More than $40 \%$ had cholesterol values between 200 and $240 \mathrm{mg} / \mathrm{dL}$, and around $10 \%$ had values $>240 \mathrm{mg} / \mathrm{dL}$. Furthermore, only $38 \%$ of participants that were in the 'don't know' group had normal cholesterol levels, with no differences between genders (figure 1).
Factors associated with 'normal' self-predicted cholesterol levels are shown in table 2. In the adjusted model, there was a direct association for female gender (OR 1.43, 95\% CI 1.27 to 1.73 ) and normal BMI (OR 1.15, 95\% CI 1.01 to 1.35 ) with normal self-reported cholesterol.

Table 2 Factors predictive of normal self-predicted cholesterol level

\begin{tabular}{|c|c|c|c|c|}
\hline \multirow[b]{3}{*}{ Variable } & \multirow{3}{*}{$\begin{array}{l}\begin{array}{l}\text { Self-predicted } \\
\text { cholesterol }\end{array} \\
\text { 'Normal' } \\
(\mathrm{n}=1285)\end{array}$} & \multirow{3}{*}{$\begin{array}{l}\text { Self-predicted } \\
\text { cholesterol } \\
\text { 'High/Don't Know' } \\
(\mathrm{n}=1755)\end{array}$} & \multirow{3}{*}{$\begin{array}{l}\text { Unadjusted OR }(95 \% \\
\mathrm{Cl})\end{array}$} & \multirow[b]{3}{*}{ Adjusted OR (95\% Cl) } \\
\hline & & & & \\
\hline & & & & \\
\hline \multicolumn{5}{|l|}{ Age, years } \\
\hline$<45$ & 297 & 321 & 1.0 (Referent) & 1.0 (Referent) \\
\hline $45-65$ & 538 & 901 & 0.65 (0.54 to 0.79$)$ & 0.67 (0.54 to 0.82$)$ \\
\hline$>65$ & 450 & 533 & $0.90(0.73$ to 1.10$)$ & 0.88 (0.69 to 1.11$)$ \\
\hline \multicolumn{5}{|l|}{ Gender } \\
\hline Male & 565 & 617 & 1.0 (Referent) & 1.0 (Referent) \\
\hline Female & 720 & 1138 & $1.44(1.25$ to 1.67$)$ & $1.48(1.27$ to 1.73$)$ \\
\hline \multicolumn{5}{|c|}{ Current smoking } \\
\hline Yes & 206 & 292 & 1.0 (Referent) & 1.0 (Referent) \\
\hline No & 1079 & 1463 & 1.01 (0.83 to 1.22$)$ & $0.92(0.75$ to 1.13$)$ \\
\hline \multicolumn{5}{|c|}{ Healthy diet } \\
\hline No & 474 & 662 & 1.0 (Referent) & 1.0 (Referent) \\
\hline Yes & 811 & 1093 & $1.03(0.89$ to 1.19$)$ & $1.08(0.93$ to 1.27$)$ \\
\hline \multicolumn{5}{|c|}{ Physically active } \\
\hline No & 591 & 818 & 1.0 (Referent) & 1.0 (Referent) \\
\hline Yes & 694 & 937 & $1.03(0.89$ to 1.19$)$ & $1.00(0.86$ to 1.16$)$ \\
\hline \multicolumn{5}{|c|}{$\mathrm{BMI}, \mathrm{kg} / \mathrm{m}^{2}$} \\
\hline$\geq 25$ & 649 & 914 & 1.0 (Referent) & 1.0 (Referent) \\
\hline$<25$ & 636 & 841 & $1.06(0.92$ to 1.22$)$ & 1.15 (1.01 to 1.35$)$ \\
\hline \multicolumn{5}{|c|}{ Blood pressure $†$} \\
\hline High & 676 & 909 & 1.0 (Referent) & 1.0 (Referent) \\
\hline Normal & 579 & 790 & $0.99(0.86$ to 1.15$)$ & 1.01 (0.85 to 1.19$)$ \\
\hline \multicolumn{5}{|l|}{ Diabetes $†$} \\
\hline Yes & 1189 & 1652 & 1.0 (Referent) & 1.0 (Referent) \\
\hline No & 91 & 95 & 0.74 (0.55 to 1.01$)$ & 0.79 (0.58 to 1.07$)$ \\
\hline
\end{tabular}

${ }^{*}$ Adjusted simultaneously for all the variables listed.

†86 missing data for blood pressure and 13 missing data for diabetes.

BMI, body mass index. 

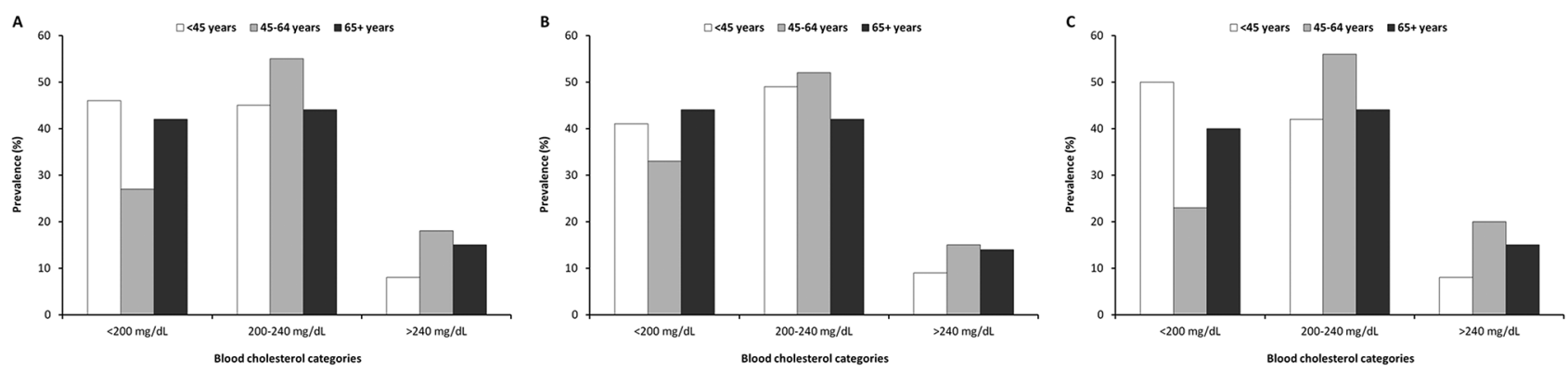

Figure 2 Total blood cholesterol levels among participants who did not check cholesterol in the past year ( $n=1201)$ according to age groups in the whole sample (A), in men (B) and in women (C).

Forty per cent of participants had not measured cholesterol in the past year, with no differences between men and women ( $39 \%$ vs $40 \%$, respectively, $\mathrm{p}=0.66$ ) (table 1 ). Among these participants, only $36 \%$ had normal cholesterol levels (figure 1). Figure 2 shows the prevalence of cholesterol levels among enrolees who had not checked cholesterol in the past year according to age groups. In the middle age group (45-64 years), a higher prevalence of people with abnormal cholesterol levels was observed $(55 \%$ 200-240 mg/dL; $18 \%>240 \mathrm{mg} / \mathrm{dL}$ ). The prevalence of abnormal cholesterol levels was significantly higher in women than in men ( $77 \%$ vs $62 \%$, respectively; $\mathrm{p}<0.001)$.

Factors associated with no cholesterol screening in the past year are shown in table 3 . In the adjusted model,

\begin{tabular}{|c|c|c|c|c|}
\hline Variable & $\begin{array}{l}\text { Cholesterol checked } \\
(n=1869)\end{array}$ & $\begin{array}{l}\text { No cholesterol check } \\
(n=1171)\end{array}$ & $\begin{array}{l}\text { Unadjusted } \\
\text { OR }(95 \% \mathrm{Cl})\end{array}$ & Adjusted OR ${ }^{\star}(95 \% \mathrm{Cl})$ \\
\hline \multicolumn{5}{|l|}{ Age, years } \\
\hline$<45$ & 257 & 357 & 1.0 (Referent) & 1.0 (Referent) \\
\hline $45-65$ & 907 & 536 & 0.42 (0.35 to 0.51$)$ & 0.46 (0.37 to 0.57$)$ \\
\hline$>65$ & 705 & 278 & $0.29(0.24$ to 0.36$)$ & 0.36 (0.28 to 0.47$)$ \\
\hline \multicolumn{5}{|l|}{ Gender } \\
\hline Female & 1132 & 726 & 1.0 (Referent) & 1.0 (Referent) \\
\hline Male & 737 & 445 & 1.05 (0.90 to 1.22$)$ & $1.11(0.95$ to 1.31$)$ \\
\hline \multicolumn{5}{|c|}{ Current smoking } \\
\hline No & 1613 & 929 & 1.0 (Referent) & 1.0 (Referent) \\
\hline Yes & 256 & 242 & 1.58 (1.31 to 1.92$)$ & 1.38 (1.12 to 1.69$)$ \\
\hline \multicolumn{5}{|c|}{ Healthy diet } \\
\hline Yes & 1247 & 657 & 1.0 (Referent) & 1.0 (Referent) \\
\hline No & 622 & 514 & 1.54 (1.33 to 1.79$)$ & 1.39 (1.18 to 1.63$)$ \\
\hline \multicolumn{5}{|c|}{ Physically active } \\
\hline Yes & 1034 & 597 & 1.0 (Referent) & 1.0 (Referent) \\
\hline No & 837 & 574 & 1.18 (1.02 to 1.37$)$ & 1.09 (0.93 to 1.28$)$ \\
\hline \multicolumn{5}{|c|}{$\mathrm{BMI}, \mathrm{kg} / \mathrm{m}^{2}$} \\
\hline$<25$ & 884 & 593 & 1.0 (Referent) & 1.0 (Referent) \\
\hline$\geq 25$ & 985 & 578 & 1.13 (0.98 to 1.31$)$ & 1.04 (0.88 to 1.22$)$ \\
\hline \multicolumn{5}{|c|}{ Blood pressure $\dagger$} \\
\hline Normal & 770 & 599 & 1.0 (Referent) & 1.0 (Referent) \\
\hline High & 1051 & 534 & $0.66(0.57$ to 0.77$)$ & 0.91 (0.77 to 1.09$)$ \\
\hline \multicolumn{5}{|l|}{ Diabetes† } \\
\hline No & 1728 & 1113 & 1.0 (Referent) & 1.0 (Referent) \\
\hline Yes & 133 & 53 & 0.61 (0.44 to 0.84$)$ & 0.73 (0.52 to 1.03$)$ \\
\hline
\end{tabular}

${ }^{*}$ Adjusted simultaneously for all the variables listed.

†86 missing data for blood pressure and 13 missing data for diabetes.

BMI, body mass index. 
older age was inversely associated with no cholesterol check, indicating that older people were more likely to control this cardiovascular risk factor. Current smoking (OR 1.38, 95\% CI 1.12 to 1.69 ) and unhealthy diet (OR $1.39,95 \%$ CI 1.18 to 1.63 ) were directly associated with the absence of cholesterol check in the past year.

Finally, we analysed cholesterol levels among participants who had not checked their cholesterol in the past year and believed to have a normal value $(n=437)$. In this subsample, only 198 (45\%) persons had normal values, $203(47 \%)$ had cholesterol between 200 and $240 \mathrm{mg} / \mathrm{dL}$ and $36(8 \%)$ had values $>240 \mathrm{mg} / \mathrm{dL}$.

\section{DISCUSSION}

We explored the prevalence of abnormal cholesterol levels and cholesterol awareness in a large and unselected sample of community-dwelling persons. We also compared rates of awareness and check of cholesterol levels between age groups and genders.

Overall, abnormal blood cholesterol was highly prevalent in our sample and less than half of individuals were aware of their cholesterol values. Indeed, more than half of participants who believed they had normal cholesterol levels showed abnormal values. Similarly, among those who had not checked cholesterol in the past year (40\%), almost two thirds (64\%) had abnormal cholesterol levels. This rate was even higher in middle-aged participants (45-64 years) with a prevalence of 73\%. Some gender differences were observed, with women who had not checked cholesterol in the past year being more likely to have high values compared with men.

Only $36 \%$ of participants had normal cholesterol values. The same prevalence was determined in a large sample of unselected Italian community dwellers. ${ }^{15}$ This rate is disappointingly low, especially considering the high prevalence of other risk factors potentially modifiable through lifestyle adjustments (ie, smoking, sedentariness and unhealthy diet) or pharmacological treatments (ie, blood glucose and blood pressure). The prevalence of dyslipidaemia unawareness in the Lookup 7+ sample $(52 \%)$ was strikingly similar to that found in a previous small-scale Italian survey $(56.9 \%),{ }^{16}$ but it was higher than in the National Health and Nutrition Examination Survey (NHANES) (49\%). ${ }^{17}$ It should however be noted that the latter study also included participants on cholesterol-lowering medications, who may be expected to have better knowledge of their blood lipid profile. In contrast, enrolees on lipid-lowering drugs were excluded from the present analysis. Our data show that the 45-64 years age group is particularly critical. Indeed, in this subset, we observed a higher prevalence of uncontrolled cholesterol levels, especially in women. This observation is in line with the NHANES, in which the 45-64 years age group showed the highest blood cholesterol levels. ${ }^{17}$ Similar to previous observations, ${ }^{15}$ this age group is also characterised by the lowest prevalence of cholesterol awareness. Furthermore, in middle age, there is a significantly increased prevalence of all other risk factors, as evidenced by the decline in the cardiovascular health metrics score after younger age. ${ }^{611}$ Finally, in keeping with previous surveys, ${ }^{15-17}$ our data show that younger individuals, smokers and those on unhealthy diet are at higher risk of not having checked cholesterol in the past year.

The burden associated with high blood cholesterol represents a prevalent and growing issue requiring effective preventive policies on a large scale and the planning of short-term and long-term goals. Anticipation of risk factor development (ie, primordial prevention) may be the most effective measure for this purpose. Indeed, blood cholesterol was identified by the American Heart Association as one of the most important factors to consider. ${ }^{18}$ Nevertheless, in Europe, the same long-term policies have been planned in small contexts and little data are available about the prevalence and distribution of cholesterol control and awareness. ${ }^{19} 20$

Our findings together with those of previous studies indicate that new public health strategies that go beyond simple, often disregarded lifestyle recommendations are necessary to improve cardiovascular health at the population level. ${ }^{21}$ Indeed, gaps in cholesterol awareness and screening are often related to availability of, access to or continuity of healthcare. Public health programmes to raise cholesterol awareness, increase the proportion of cholesterol screening and achieve better cholesterol control are needed. To this aim, the Lookup 7+ initiative may represent a prototypical approach to promote the recognition and management of unhealthy behaviours and modifiable cardiovascular risk factors in the general population.

\section{Limitations}

Some limitations of our study should be considered in the interpretation of results. Random cholesterol and glucose determinations could lead to overestimating both parameters. Conventionally, blood samples for lipid analysis are drawn in the fasting state. However, fasting and non-fasting sampling gives similar results for total cholesterol, low-density lipoprotein (LDL) cholesterol and high-density lipoprotein (HDL) cholesterol. Cholesterol and glucose were measured in capillary blood samples. Although the procedure was previously validated, ${ }^{12}$ the error of portable devices is higher than with standard equipment. Only total cholesterol was analysed and no information on LDL and HDL cholesterol was available. Nevertheless, total cholesterol is typically used for cardiovascular risk estimation in CVD risk prediction charts. The type of evaluation and its setting could also influence the assessment of health metrics. Indeed, people who decided to participate were involved-before being assessed-in usual exhibition and/or shopping centre activities, such as walking, carrying bags and eating, which could have influenced the assessment. Furthermore, alcohol and coffee drinking, which may affect blood pressure and blood lipids levels, was not recorded or controlled for. In order not to overburden the participants and keep the duration of evaluations within a reasonable time range, 
waist circumference, which is considered to be a better indicator of abdominal fatness and cardiometabolic risk than BMI, was not measured. However, BMI has shown to be predictive of cardiovascular events in the context of multivariable prediction algorithms. ${ }^{22}$ Because information on socioeconomic characteristics and education was not collected, the impact of social status and health literacy on cardiovascular risk awareness could not be established. Our results were obtained from a cross-sectional survey. As such, some findings could be explained by differences in the birth cohort rather than reflecting true age-related patterns. Finally, the Lookup 7+ population included only Caucasians, which impedes the generalisability of our results to other ethnic groups.

\section{CONCLUSIONS}

In terms of public health and active longevity, adulthood is the most important age for the implementation of specific screening and prevention programmes. ${ }^{23}$ The Lookup $7+$ isan easy, reproducible and relatively inexpensive screening approach that may be used as a model to promote public health, especially outside of conventional healthcare settings. Through specific programmes such as the Lookup $7+$, it is indeed possible to promote awareness about the importance of preventative strategies among persons who otherwise would not undergo any screening.

Acknowledgements The authors thank the entire Lookup 7+ team (Vincenzo Brandi, Marianna Broccatelli, Agnese Collamati, Giuseppe Colloca, Emanuela D'Angelo, Mariaelena D'Elia, Domenico Fusco) for their great enthusiasm in performing participant assessments.

Contributors Conceived and designed the analyses: ASi, EM, RC and FL. Analysed the data: ASi, AP and MT. Coordinated participant recruitment and performed participant assessments: AMM, EO, SS and TP. Drafted the paper: ASa and LS. Supervised the project and edited the manuscript: RB. All authors read and approved the final manuscript.

Funding The Lookup 7+ project was supported by Italia Longeva, Marche Region, Ferrarini, Tedaldi, Fileni, Elanco, Danone Italia and Merck Sharp \& Dohme Italia. The study was also partly supported by intramural research grants from the Catholic University of the Sacred Heart (D3.2 2013 and D3.2 2015) to FL and by the non-profit research foundation 'Centro Studi Achille e Linda Lorenzon' (AP, EM, RC).

\section{Competing interests None declared.}

Patient consent Not required.

Ethics approval The study protocol was approved by the Catholic University of the Sacred Heart Ethics Committee.

Provenance and peer review Not commissioned; externally peer reviewed.

Data sharing statement Data will be made available with no restriction upon reasonable request at francesco.landi@unicatt.it.

Open access This is an open access article distributed in accordance with the Creative Commons Attribution Non Commercial (CC BY-NC 4.0) license, which permits others to distribute, remix, adapt, build upon this work non-commercially, and license their derivative works on different terms, provided the original work is properly cited, appropriate credit is given, any changes made indicated, and the use is non-commercial. See:Chttp://creativecommons.org/licenses/by-nc/4.0/.

\section{REFERENCES}

1. Ray KK, Kastelein JJ, Boekholdt SM, et al. The ACC/AHA 2013 guideline on the treatment of blood cholesterol to reduce atherosclerotic cardiovascular disease risk in adults: the good the bad and the uncertain: a comparison with ESC/EAS guidelines for the management of dyslipidaemias 2011. Eur Heart J 2014;35:960-8.

2. Laaksonen M, Talala K, Martelin T, et al. Health behaviours as explanations for educational level differences in cardiovascular and all-cause mortality: a follow-up of 60000 men and women over 23 years. Eur J Public Health 2008;18:38-43.

3. Roger VL, Go AS, Lloyd-Jones DM, et al. Executive summary: heart disease and stroke statistics--2012 update: a report from the American Heart Association. Circulation 2012;125:188-97.

4. Ose D, Rochon J, Campbell SM, et al. Health-related quality of life and risk factor control: the importance of educational level in prevention of cardiovascular diseases. Eur J Public Health 2014;24:679-84.

5. GBD. Eastern Mediterranean Region Cardiovascular Disease Collaborators $\mathrm{AH}$, Mokdad AH. Burden of cardiovascular diseases in the Eastern Mediterranean Region, 1990-2015: findings from the Global Burden of Disease 2015 study. Int J Public Health 2015;2017.

6. Vetrano DL, Martone AM, Mastropaolo S, et al. Prevalence of the seven cardiovascular health metrics in a Mediterranean country: results from a cross-sectional study. Eur $J$ Public Health 2013:23:858-62.

7. Landi F, Calvani R, Tosato M, et al. Age-Related Variations of Muscle Mass, Strength, and Physical Performance in CommunityDwellers: Results From the Milan EXPO Survey. J Am Med Dir Assoc 2017;18:88.e17-88.e24.

8. Landi F, Calvani R, Tosato M, et al. Animal-Derived Protein Consumption Is Associated with Muscle Mass and Strength in Community-Dwellers: Results from the Milan EXPO Survey. J Nutr Health Aging 2017;21:1050-6.

9. Marzetti E, Hwang AC, Tosato M, et al. Age-related changes of skeletal muscle mass and strength among Italian and Taiwanese older people: Results from the Milan EXPO 2015 survey and the I-Lan Longitudinal Aging Study. Exp Gerontol 2018;102:76-80.

10. Landi F, Calvani R, Picca A, et al. Cardiovascular health metrics, muscle mass and function among Italian community-dwellers: the Lookup 7+ project. Eur J Public Health 2018.

11. Yang Q, Cogswell ME, Flanders WD, et al. Trends in cardiovascular health metrics and associations with all-cause and CVD mortality among US adults. JAMA 2012;307:1273-83.

12. Rapi S, Bazzini C, Tozzetti C, et al. Point-of-care testing of cholesterol and triglycerides for epidemiologic studies: evaluation of the multicare-in system. Transl Res 2009;153:71-6.

13. American Diabetes Association AD. 2. Classification and Diagnosis of Diabetes. Diabetes Care 2017;40(Suppl 1):S11-24.

14. Mancia G, De Backer G, Dominiczak A, et al. Guidelines for the management of arterial hypertension: The Task Force for the Management of Arterial Hypertension of the European Society of Hypertension (ESH) and of the European Society of Cardiology (ESC). Eur Heart J 2007;2007:1462-536.

15. Grassi G, Arenare F, Dell'oro R, et al. Prevalence of cardiovascular risk factors in an unselected italian population. Results of the Cardiolab Project 2004-2008. Acta Cardiol 2009;64:771-8.

16. Omboni S, Carabelli G, Ghirardi E, et al. Awareness, treatment, and control of major cardiovascular risk factors in a small-scale Italian community: results of a screening campaign. Vasc Health Risk Manag 2013;9:177-85.

17. Ford ES, Mokdad AH, Giles WH, et al. Serum total cholesterol concentrations and awareness, treatment, and control of hypercholesterolemia among US adults: findings from the National Health and Nutrition Examination Survey, 1999 to 2000. Circulation 2003;107:2185-9.

18. Lloyd-Jones DM, Hong Y, Labarthe D, et al. Defining and setting national goals for cardiovascular health promotion and disease reduction: the American Heart Association's strategic Impact Goal through 2020 and beyond. Circulation 2010;121:586-613.

19. Laaser U, Breckenkamp J. Trends in risk factor control in Germany 1984-1998: high blood pressure and total cholesterol. Eur J Public Health 2006;16:217-22.

20. Pilav A, Nissinen A, Haukkala A, et al. Cardiovascular risk factors in the Federation of Bosnia and Herzegovina. Eur J Public Health 2007;17:75-9.

21. Expert Panel on Detection, Evaluation, and Treatment of High Blood Cholesterol in Adults. Executive Summary of The Third Report of The National Cholesterol Education Program (NCEP) Expert Panel on Detection, Evaluation, And Treatment of High Blood Cholesterol In Adults (Adult Treatment Panel III). JAMA 2001;285:2486-97.

22. D'Agostino RB, Vasan RS, Pencina MJ, et al. General cardiovascular risk profile for use in primary care: the Framingham Heart Study. Circulation 2008; $117: 743-53$.

23. Landi F, Calvani R, Picca A, et al. Impact of habitual physical activity and type of exercise on physical performance across ages in community-living people. PLoS One 2018;13:e0191820. 